\title{
A Rare Potential Cause of Extraluminal Left Main Compression in ASD: An Echocardiographic Illustration
}

\author{
Jasvinder Kaur Kohli ${ }^{1}$ Armaanjeet Singh ${ }^{1} \quad$ Ashish Walian $^{1} \quad$ Noopur Bansal ${ }^{1} \quad$ Rohan Magoon ${ }^{1}$ \\ Ramesh Chand Kashav ${ }^{1}$
}

${ }^{1}$ Department of Cardiac Anaesthesia, Atal Bihari Vajpayee Institute of Medical Sciences (ABVIMS) and Dr. Ram Manohar Lohia Hospital, New Delhi, India52163164

Address for correspondence Ramesh Chand Kashav, MD, Department of Cardiac Anaesthesia, Atal Bihari Vajpayee Institute of Medical Sciences (ABVIMS) and Dr. Ram Manohar Lohia Hospital, Baba Kharak Singh Marg, New Delhi 110001, India (e-mail:drkashav@yahoo.co.in).

J Card Crit Care 2021;5:157-158.

While atrial septal defect (ASD) classifies as the most common cause of grown-up congenital heart (GUCH) disease, it can present with unconventional symptoms, owing to the underlying pathophysiological alterations. ${ }^{1}$ Atypical chest pain in ASD can be due to arrhythmias, right ventricular dysfunction, or ischemia. However, we describe an interesting echocardiographic finding, showcasing a rare potential cause of left main coronary artery (LMCA), resulting in chest pain in patients with ASD.

Although asymptomatic survival to adulthood is common, patients can present with pulmonary arterial enlargement, owing to varying degrees of pulmonary arterial hypertension. This can result in grossly distended pulmonary arteries. The left main coronary artery arises just above the left Sinus of Valsalva and courses behind the pulmonary trunk. It travels for a very short distance along the epicardium between the pulmonary trunk and aorta before dividing into anterior descending and circumflex arteries. ${ }^{2}$ The expansion of pulmonary artery can manifest as a cause of extraluminal/dynamic LMCA compression. ${ }^{3-5}$ This can masquerade as ischemic heart disease, despite the absence of any coronary artery atherosclerosis.

We hereby present a case of a 40-year-old female with complaints of chest pain who was brought to the Cardiothoracic Intensive Care Unit (CTVS ICU) when she developed ventricular ectopics and ST segment changes on EKG monitoring. The transesophageal echocardiography (TEE), performed using Philips Epiq 7 (Bothell, WA) X7-2T
TEE Probe (2-6 MHz), revealed a large ostium secundum ASD measuring $4.2 \mathrm{~cm}$ with left-to-right shunt. The patient had dilated right atrium (RA), right ventricle (RV), left atrium (LA), and pulmonary artery (PA). On midesophageal aortic valve short axis (SA) view ( - Fig. 1), the LMCA appeared to be significantly narrowed (diameter $-0.24 \mathrm{~cm}$ ). The PA, in the midesophageal ascending aortic SA view ( - Figs. 2 and 3), was grossly dilated (diameter $-3.8 \mathrm{~cm}$ ), dynamically compressing the LMCA. The dynamic compression is evident in this view, as seen in the video clip ( - Video 1 ). The TEE findings were subsequently confirmed using $\mathrm{CT}$ angiography, and the patient was planned for ASD closure with coronary artery bypass graft (CABG) surgery. ASD closure using dacron patch and left internal mammary artery to left anterior descending artery graft was performed. Following the surgery, patient was placed on mechanical ventilation in ICU for 8 hours and then successfully extubated with no adverse events.

\section{Video 1 \\ Two-dimensional transesophageal echocardiography (2D TEE), midesophageal ascending aortic short axis (SA) view, showed dynamic compression left main coronary artery (LMCA) course between ascending aorta (Asc Ao) and pulmonary artery (PA). Online content including video sequences viewable at: https://www.thieme-connect. com/products/ejournals/html/10.1055/s-0041-1732840.}

\section{published online}

August 5, 2021
DOI https://doi.org/

$10.1055 / \mathrm{s}-0041-1732840$

ISSN 2457-0206 (c) 2021. Official Publication of The Simulation Society (TSS), accredited by International Society of Cardiovascular Ultrasound (ISCU).

This is an open access article published by Thieme under the terms of the Creative Commons Attribution-NonDerivative-NonCommercial-License, permitting copying and reproduction so long as the original work is given appropriate credit. Contents may not be used for commercial purposes, or adapted, remixed, transformed or built upon. (https://creativecommons.org/licenses/by-nc-nd/4.0/).

Thieme Medical and Scientific Publishers Pvt. Ltd. A-12, 2nd Floor, Sector 2, Noida-201301 UP, India 


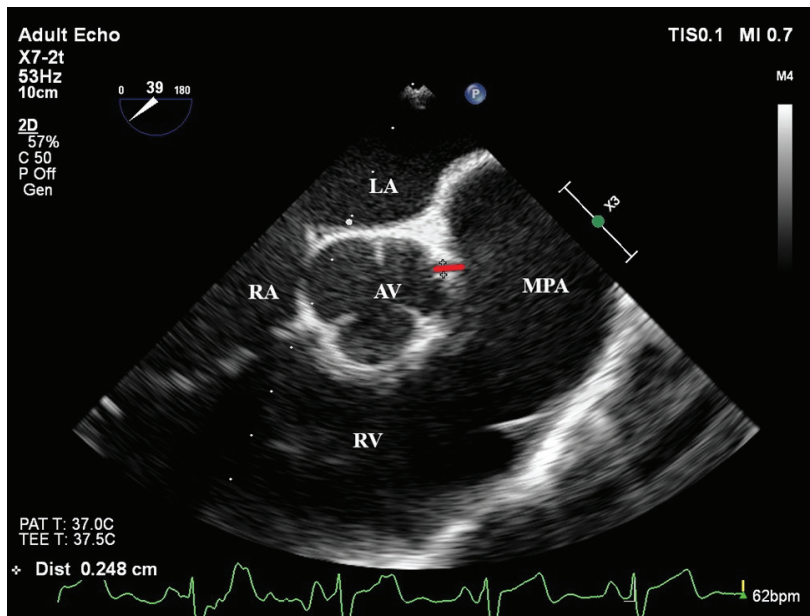

Fig. 1 Two-dimensional transesophageal echocardiography (2D TEE), midesophageal aortic valve short axis (SA) view, showed narrowing of left main coronary artery (LMCA). LA, left atrium; RA, right atrium; AV, aortic valve; RV, right ventricle; MPA, main pulmonary artery.

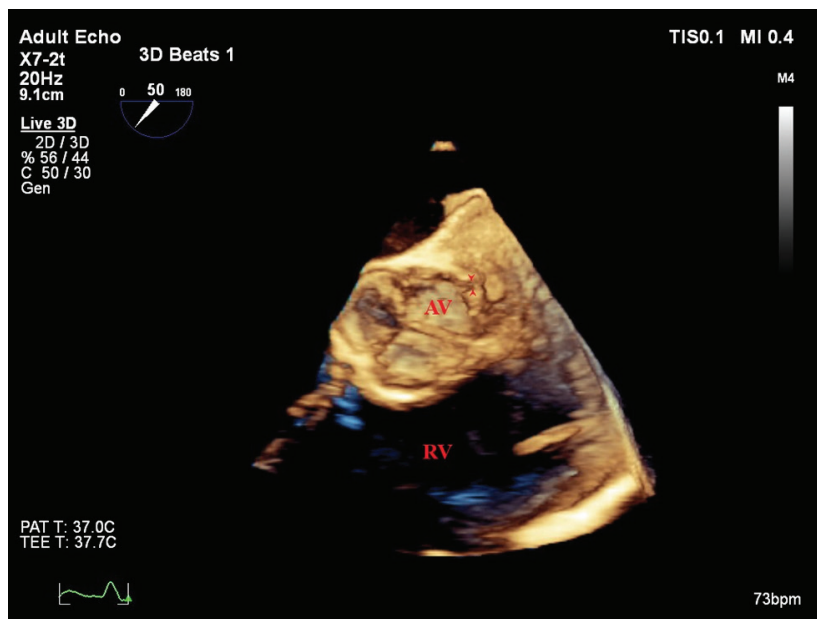

Fig. 2 Three-dimensional transesophageal echocardiography (3D TEE), midesophageal aortic valve short axis (SA) view, showed left main coronary artery (LMCA) (arrows) located adjacent to the aortic valve (AV) with apparent extraluminal stenosis. RV, right ventricle.

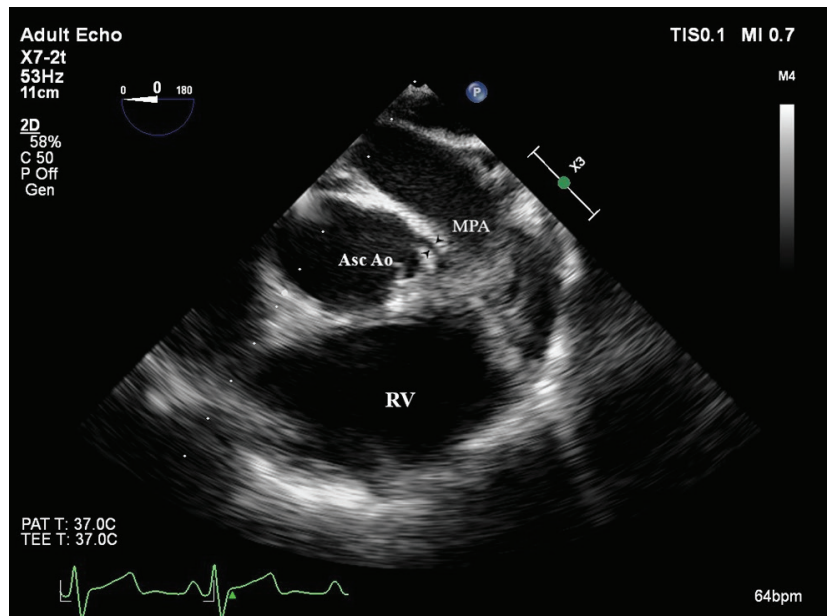

Fig. 3 Two-dimensional transesophageal echocardiography (2D TEE), midesophageal ascending aortic short axis (SA) view, showed left main coronary artery (LMCA) course (arrows) between ascending aorta (Asc Ao) and pulmonary artery (PA). RV, right ventricle; MPA, main pulmonary artery.

\section{Conflict of Interest}

We do not have any conflict of interest or any commercial or financial interest in this material. We agree to abide by the rules of your journal regarding publication of this article.

\section{References}

1 Seldon WA, Rubinstein C, Fraser AA. The incidence of atrial septal defect in adults. Br Heart J 1962;24(5):557-560

2 Weyman AE, Feigenbaum H, Dillon JC, Johnston KW, Eggleton RC. Noninvasive visualization of the left main coronary artery by cross-sectional echocardiography. Circulation 1976;54(2):169-174

3 Piña Y, Exaire JE, Sandoval J. Left main coronary artery extrinsic compression syndrome: a combined intravascular ultrasound and pressure wire. J Invasive Cardiol 2006;18(3):E102-E104

4 Labin JE, Saggar R, Yang EH, et al. Left main coronary artery compression in pulmonary hypertension. Catheter Cardiovasc Interv 2020;(e-pub ahead of print). doi: 10.1002/ccd.29401

5 Verheijen DBH, Meijer FMM, Kiès P, Egorova AD. Pulmonary hypertension causing left main coronary artery compression. Eur Heart J Case Rep 2020;4(5):1-3 